International Journal of Instruction e-ISSN: 1308-1470 • www.e-iji.net
July $2018 \bullet$ Vol.11, No.3

p-ISSN: 1694-609X

pp. 347-362

Received: 11/01/2018

Revision: 23/03/2018

Accepted: 28/03/2018

\title{
Effect of Teacher Motivational Practices and Student Demotivation on Request and Refusal Speech Acts Produced by Iranian EFL Learners
}

\author{
Ahmad Molavi \\ Ph.D in TEFL, corresponding author, Department of English, Isfahan Branch \\ (Khorasgan), Islamic Azad University, Isfahan, Iran, tfl2015@yahoo.com \\ Reza Biria \\ Assoc. Prof., Department of English, Isfahan Branch (Khorasgan), Islamic Azad \\ University, Isfahan, Iran, biria_reza@yahoo.com
}

\section{Azizeh Chalak}

Asst. Prof., Department of English, Isfahan Branch (Khorasgan), Islamic Azad University, Isfahan, Iran, azizeh_chalak@yahoo.com

This study aimed at examining the possible effects of teacher motivational practices and student demotivation on the way Iranian English as a Foreign Language (EFL) learners produce request and refusal speech acts. Subsequently, four instruments were selected and administered to the participants under scrutiny. They were: (a) a Quick Placement Test, (b) the Motivational Orientation of Language Teaching classroom observation scheme, (c) the Post-Lesson Teacher Evaluation scale, and (d) a Discourse Completion Task. The analyses of the related data obtained from the targeted participants revealed significant differences between students in high and low motivation groups with respect to the production of request and refusal speech acts on the post-test scores. It was observed that various levels of demotivation dramatically influence the quality of request and refusal speech acts produced by the learners in their English classes. Alternatively, the findings demonstrated that teachers' motivational practices had a direct bearing on the learners' productions of the targeted speech acts. Notably, the results of the study may offer insightful benefits to textbook developers, EFL teachers, and stakeholders involved in the language teaching profession.

Keywords: teacher motivational practice, demotivation, request speech act, refusal speech act, EFL

\section{INTRODUCTION}

Throughout the time, cultures have developed their own rules of appropriateness of verbal behavior particularly regarding politeness and other successful communication

Citation: Molavi, A., Biria, R., \& Chalak, A. (2018). Effect of Teacher Motivational Practices and Student Demotivation on Request and Refusal Speech Acts Produced by Iranian EFL Learners. International Journal of Instruction, 11(3), 347-362. https://doi.org/10.12973/iji.2018.11324a 
devices. Members of every culture tend to interpret communications based on their own pragmatics and sociolinguistic parameters. Therefore, when a cross-cultural communication takes place, people from different cultures decode behavior or utterances according to such rules, and when facing controversies they might miss the key points, interpret such language as inappropriate and consequently, lead to communication breakdowns. In addition, the stereotypical labeling of non-native speakers as rude, insensitive, or inept is possible (Eslami-Rasekh, 2005). As Memarian (2012) mentions having the knowledge of pragmatics differences among cultures and knowing appropriate ways of production of request and refusal speech acts in other languages may help minimize the negative effects regarding unintentional rudeness and maximize the quality of the communication.

Speech act theory is the study of how language is used and the effects of language use upon hearers. The emphasis is not only what is spoken but also the consideration of the performative utterance in what it does and its resulting effects (Austin 1975:6-7). Speech act theory addresses how we use speech (locutionary act), the performance of an act in saying something (illocutionary act), and the consequential effect or intended result of saying something (perlocutionary act) (Austin 1975, pp. 98-103). Communication in both first language (L1) and second language (L2) entails the appropriate use of speech acts, and failure to do so can result in numerous difficulties. As White (1993) notes, 'attempts at being polite can come unstuck through unwitting violation of speech act rules, so that although an utterance is grammatically well formed, it may be functionally confusing or contextually inappropriate' (p. 193).

The theory of speech act (Searl, 1969) and politeness (Leech, 1983, p. 66) are the two fields of pragmatics affecting second language acquisition. Wolfson (1983) notes that 'sociolinguistic rules are subject to considerable variation with respect to region and status' (1983, p. 66). Therefore, communities have linguistic formulas to pinpoint politeness of their members as it is important to keep the harmony in the community. However, second language learners, not familiar with such rules, may have difficulty adjusting (Wolfson, 1983).

As Jalilifar (2009) mentions, requests have become more popular in the last decades in the field of research. Koike (1989) believes that 'speech act of requests are particularly important to beginning L2 learners since most of their future interaction with native speakers of L2, if there is any at all, will probably take place in the form of requests' ( $p$. 280).

Refusal on the other hand is a type of speech act that is projected as a response to another individual's request, invitation, offer or suggestion which means it is not speaker initiative (Hassani, Mardani, \& Hossein, 2011). Since refusal is a speech act potentially including a level of rudeness and discourtesy, performing inappropriate refusal strategies may harm the relationship between interlocutors. Thus, proper perception of refusals requires a certain degree of cultural awareness (Hassani, Mardani, \& Hossein, 2011). Reviewing the available literature on teacher motivational practice in the Iranian context highlights some important points which deserve further attention. In the majority of cases, teacher motivational practice has been conceptualized as a stable and constant 
construct which could be objectively observed, evaluated, and measured (e.g., Hein, 2012; Mehrpour et al., 2016; Alemi and Khanlarzadeh, 2017, and MashhadiHeidar et al., 2017).

Despite the significant contribution of the research which has been reviewed to the understanding of the role of EFL teachers' motivational strategies and student demotivation, the evidence provided seems to be scant and limited to a few aforementioned contexts, it seems that all of these studies have only been based on the perceived, not actual use and effectiveness motivational strategies. Furhtermore as English is considered a foriegn language in Iran and Iranian EFL learners seem to be reluctant in the production of speech acts and as no studies could be found to be focused on the relationship between Iranian EFL learners' motivation and speech acts production, the researchers considered it as an area of research which needed to be elaborated more deeply. Furthermore teacher motivational practice vs. Students' demotivation seem influential on the improvement of Iranian EFL learners' request and refusal speech acts production. Consequently, stronger evidence is required to shed light on the nature and role of teachers' motivational practice and student demotivation on improving Iranian EFL learners' request and refusal speech acts production in instructed second language acquisition. Following Guilloteaux and Dörnyei (2008), the objective of the study was to investigate the relationship between L2 teachers' motivational practice vs. student demotivation and EFL learners' production of request and refusal speech acts. So, the following research questions were formulated to achieve the objectives of the study:

Q1. Does teacher motivational practice influence Iranian EFL learners' production of request speech acts?

Q2. To what extent does teacher motivational practice influence Iranian EFL learners' production of refusal speech acts?

Q3. What is the relationship between student demotivation and Iranian EFL Learners' production of request and refusal speech acts?

\section{LITERATURE REVIEW}

Considering the importance of the role of motivational factors on the realization and production of speech acts, different researchers have studied the point from different angles. Hein (2012) tried to bring together insights from research on teacher motivational behavior related with student's motivation and learning in physical education. Teacher behavior is analyzed in terms of two independent behavior dimensions called teacher interpersonal behavior and teaching styles (methods). The analysis is based on self-determination theory. More specifically, the effect of the autonomy supportive and controlling teacher on student's motivation and learning outcome in physical education context are discussed. Papi and Abdollahzadeh (2012) replicated the study done by Guillautaux and Dornyei and gained similar conclusions but added the need to focus more studies on motivation in tertiary settings due to the unique context of those settings. Melekoğlu and Wilkerson (2013) examined whether reading motivation of struggling readers with and without disabilities significantly changed after an eighteen week period of reading instruction in two elementary schools 
and one high school in a Midwest state of the United States of America (USA). Struggling readers with and without disabilities between grades four and twelve who were exposed to a structured, research-based reading program for students with reading difficulties at local elementary and high schools were the target of this study. Results of the study showed significant improvement in motivation for adolescents without disabilities while motivation scores declined for students with disabilities. The study also summarized some evidence-based methods that teachers can utilize to improve reading motivation of upper elementary and high school students.

Mehrpour et al. (2016) were interested to see whether pragmatic transfer of refusals among three languages spoken by the same person occurs from L1 and L2 to L3, L1 to L2 and then to L3 or from L1 and L1 (if there are more than one L1) to L2. This study aimed to investigate the production of refusals in three languages and to specify the impact of linguistic knowledge on pragmatic transfer of refusals. Results depicted that pragmatic transfer exists in choice and content of semantic formulae. It was also found that the sociocultural norms of English, Farsi, and Kurdish languages differ with respects to the refusal speech act and that individuals' social power and relative distance play a critical role in performing such a speech act. their research suggests that, in spite of the norm differences existing among these languages, transfer of refusals mostly occurs from Kurdish as L1but not from L2 (Farsi) to L3 (English).

ElahiShirvan and Taherian (2016) also investigated the dynamic factors influencing willingness to communicate (WTC) in an English as a foreign language (EFL) classroom in Iran at a private institute, over the period of one semester, from an ecological perspective. Six students ( 2 males and 4 females) participated in their study allowing intensive, individual-level microanalysis. Data were collected through semistructured interviews, classroom observations, and learning journals. Qualitative content analysis was applied to the data through reading, coding and revising the codes which were later analyzed by MAXQDA in light of Bronfenbrenner's ( 1993) nested ecosystems model as an analytical framework. Six WTC factors within the microsystem of classroom ecology were recognized: cognitive factors, linguistic factors, and affective factors. In addition, factors at the meso-, exo-, and macrosystem and their effect on classroom WTC were explained. Study results shed light on an ecological understanding of the dynamics of Iranian EFL students' WTC in language classrooms.

Alemi and Khanlarzadeh (2017) aimed to investigate the native and non-native EFL teachers' rating scores and criteria regarding the speech act of request. To this end, 50 American ESL teachers and 50 Iranian EFL teachers participated to rate the EFL learners' responses to video-prompted Discourse Completion Tests (DCTs) regarding the speech act of request. The result proved that there are significant differences between native and non-native EFL teachers' rating pattern. The results of this study also emphasized on importance of sociopragmatic and pragmalinguistic features in native and non-native teachers' pragmatic rating, which can have several implications for L2 teachers, learners, and material developers.

Mahmud (2017) focused on two English classes which employed classroom presentations as the learning strategy. To collect data, the researcher recorded the classroom presentations of the two classes. Twelve recordings from twelve groups of 
students were obtained, transcribed, and analyzed using discourse analysis approach. The communicative styles used by the students were discussed based on the communication strategies of Dörnyei and Scott (1997) and the students' talk was analyzed based on Brown's FLINT system (2000). Results revealed that the participants employed various styles to communicate in the classroom presentations. Their communicative styles can be in the form of speech acts, discourse markers, language choices, address terms, and the inclusion of regional terms derived from the BugisMakassar language such as the pronoun - ko and softeners -mi and -ji. Findings of this study are relevant in the development of English language teaching, particularly in effort to create effective classroom interaction.

Deveci and Hmida (2017) investigated how the request speech act set is realized by both native speakers of English and Arab university students in an English-medium university in the UAE, as well as whether or not instruction in formal email writing improves students' pragmatic competence. Data were collected using a DCT that required the participants to write an email to their professors requesting feedback. Results revealed that there were some significant differences between the data sets from native speakers of English and Arab learners of English in terms of discourse structure, strategy type, and modifiers employed.

MashhadiHeidar et al. (2017) tried to examine how the social factors influence Iranian teachers' motivation towards English as an international language. To this end, a questionnaire was used as a research instrument. It was administered to 100 Iranian teachers of Islamic Azad University, Qaemshahr, Iran. The research indicates that, concerning the notion of English as an international language, participants held different motivation towards different issues of social factors relating to English language learning.The study findings showed that social factors can influence Iranian Teachers' motivation toward English language learning.

The purpose of a study done by Kakar and Pathan (2017) was to investigate motivational strategies which EFL teachers employ to motivate students in learning English language and to determine the significant difference if any across male and female teachers in practicing motivational strategies in an EFL classroom. The findings of the present study have implications on effective English language teaching and enhancing teachers' experience and knowledge in order to motivate EFL learners by using different motivational strategies in learning English in context of Pakistan.

$\mathrm{Li}$ and Zhou (2017) investigated the relationship between demotivation and academic fields among Chinese EFL learners. To this end, a 33-item self-made questionnaire was administered to 128 Chinese tertiary EFL students. The collected data were processed by means of both descriptive and inferential analysis. The results identified eight salient demotivators: Teaching Contents and Teaching Process, Teacher-related Factors, Classroom Learning Environment and Facilities, Deficient English Learning Abilities, Lack of Intrinsic Interest, Undesired Influences of Important Others, Textbooks and Teaching Materials, and Lack of Effective Learning Strategies. The findings of this study would be implicative for helping English teachers reduce the negative effect of demotivation in college English class in China and beyond. 
Using questionnaires and group interviews, in a mixed-method design Salikin et al. (2017) investigated the Indonesian EFL learners' motivation in reading activity based on Deci and Ryans' theory of motivation including intrinsic and extrinsic. The subject of the study involved 42 freshmen students of English department, the faculty of humanities at Jember University in the academic year 2015-2016. Results unrevealed that both intrinsic and extrinsic motivations have significant contribution in motivating the learners to read the English text. The intrinsic motivation played the important role in students' reading activities. Besides, the extrinsic motivation found the teacher's role as the learners' motivator in reading the English text through their method implemented in the reading class. The researchers hope this research expectedly can help further researchers in doing observations related to motivation of Indonesian EFL learners.

Rastegari, and Narafshan (2017) focused on the impact of extensive and repeated listening strategies on EFL learners' motivation at Baft English language institutes. It was a quantitative experimental study in nature. In order to see the impact of repeated and extensive listening strategies on EFL learners' motivation, a questionnaire was used which was designed based on the questionnaires of Salimi, 2000; Dornyei, 2002 ; and Csizar and Dornyei ,2005. The results showed that implementing repeated listening strategy, but not extensive listening strategy has the potentiality of increasing EFL learners' motivation. This study has used empirical findings to show that repeated listening strategy has positive effect on increasing motivation of EFL learners and decreasing their anxiety.

Wu and Lee (2017) studied students' views of the graduation policy in three universities where students are asked to take the General English Proficiency Test (GEPT) prior to graduation. Structural equation modeling was employed to find the best fitting model that illustrates the complex interrelationships among test performance, students' perceptions of the requirement, test value, test anxiety, and learning motivation. The findings revealed that university students, regardless of English proficiency, generally hold a positive attitude towards the English graduation benchmark policy. Results also showed that the Intermediate group shows more positive attitudes towards the graduation requirement than the High-Intermediate group. The findings contribute to our understanding of university students as the major stakeholders who defined the context of test use. Regarding refusal strategies, Qadoury (2011) dealt with pragmatic transfer of Iraqi EFL learners' refusal strategies compared with Iraqi native speakers of Arabic and American native speakers of English. The DCT consisted of 12 situations including requests, offers, suggestions, and invitations with higher, equal, and lower status interlocutors. Data analyzed according to frequency types of refusal strategies and interlocutor's social status. Findings reveal that the frequency of use of refusals by Iraqi EFL learners is different from that of Americans, however they share some similarities. Iraqi EFL learners prefer to express refusals with caution by using more statements of reason, regret, wish and refusal adjuncts in their responses than Americans. Americans are more sensitive to their interlocutor's higher and equal status, whereas Iraqi EFL 100 learners to lower status.Evidences proved the existence of little difference between IEFL males and females in refusal frequency and refusal adjuncts. 
Kuhi and Jadidi (2012) attempted to investigate Iranian EFL learners' perception and production of politeness in three basic speech acts: request, refusal, and apology. The participants involved 63 MA Foreign language students. A multiple-choice Discourse Completion Test (DCT) and a politeness rating questionnaire were used to generate participant's data. The data analysis revealed that the participants had enough knowledge about speech act and politeness strategies. In requesting, they mainly relied on indirect strategies; similarly, in refusing, they had a tendency towards using indirect strategies more than direct ones; but in apologizing they acted more directly. Gender as a cultural variable had effect on face saving strategies, and based on Brown \& Levinson's politeness theory, Iranian EFL learners in this study mainly resorted to negative politeness.

In a quasi-experimental study, TamimiSa'd and Gholami (2017) investigated the effect of instructional intervention in teaching polite refusal strategies explicitly on Iranian EFL learners' performance of the speech act of refusing. The participants, consisting of 24 male elementary EFL learners aged 12-18, responded to a discourse completion task (DCT) prior to and after they had been provided with explicit instruction concerning the polite performance of refusals in English. Results showed a high level of appropriacy in the semantic content of refusal utterances compared to their responses in the pretest.In conclusion, the study revealed the positive effects of instructional intervention on the development of the pragmatic competence of learners with low linguistic proficiency levels. It is worth to mention here that all the studies mentioned above have investigated the influence of teacher motivational practice and student demotivation on different skills of second/foreign language learning, but what seems untouched is its impact on the production of request and refusal strategies, especially in the context of Iran.

And finally using a pretest and posttest control group quasiexperimental design in a recent study Veysel (2018) investigated the effects of using geometric functions approach on 9th grade students' motivation levels toward mathematics in functions unit. Participants of this study were 87 students who were ongoing in the first year of high school in Turkey. In the experimental group I, geometric functions approach and dynamic mathematics software which supported the mathematics teaching were used. dynamic mathematics software which supported the mathematics teaching was used in the experimental group II,. as the teaching method in the control group, traditional mathematics teaching method was used. The data of this study were collected using Students' Motivation toward Mathematics Learning questionnaire (SMTML). Before the experimental process, there was no statistically significant difference between students' motivation levels toward mathematics. After the experimental process, there was not a significant difference between experimental group I, experimental group II and control groups except for achievement goal dimension post-test scores. There was a statistically significant difference between groups in achievement goal dimension. Results revealed that using geometric functions approach in the learning process of function concept had a significant effect on students' achievement goal motivation. 


\section{METHOD}

\section{Research Design}

A Hybrid research design consisting of process and product stages was utilized to test the targeted hypotheses because the study involved both parametric and non-parametric data related to teachers' motivational practices, learners' demotivation and students' achievement of L2 request strategies through explicit instruction.

\section{Participants}

The study population was supposed to be all Iranian senior high school students in Iranian training and education ministry but as if the area is so vast and it is almost impossible to include all Iranian high school (male and female) students in the study, the target population of the study in hand were all Iranian EFL learners in six districts of Isfahan training and education department.From the population of teachers and students attending various school systems in the city of Isfahan, two different samples were chosen based on a convenient sampling method. The student group comprising 300 male upper intermediate level native Persian high school students from 12 classes in 6 educational districts in Isfahan, whose age level was between 15 and 17, were selected using a general English placement test; namely, Quick Placement Test (hereafter called QPT) in order to make sure that the participants were homogeneous with regard to their English language proficiency. The teacher group was alternatively twelve experienced English teachers who were purposefully selected to teach request and refusal speech acts in the final stage of the study formulated for obtaining an answer to the third research question.

\section{Instruments}

Four instruments were used to provide appropriate responses to the research questions: (a) Quick Placement Test (QPT-the original version which is used in this study and its reliability and validity has already been measured by Oxford University Press and University of Cambridge Local Examinations Syndicate) to distinguish the participants language proficiency level, (b) the Motivational Orientation of Language Teaching classroom observation scheme (MOLT) developed by Guilloteaux and D"ornyei (2008), (c) the Post-Lesson Teacher Evaluation scale, both of which were used to study teacher and student motivational behaviour in class, and (d) the Discourse Completion Task (DCT) which was developed and validated by Jalilifar (2009), translated into Persian to ascertain ease of understanding) for the measurement of the participants' request and refusal speech acts production. Notably, three translation instructors checked the quality of the Persian translation to cope with any probable pitfalls.

A word of caution deams to be mentioned here:The validity of the istruments used in the study was established based on specialists' opinion, while the reliability was measured through pilot testing. The Cronbach's alpha coeficient values for (a) Motivational Orientation of Language Teaching classroom observation scheme (MOLT), and (b) the Discourse Completion Task (DCT) were .76, and .79 respectively. Furthermore the reliability and validity of the QPT had already been stablished by Oxford University Press and University of Cambridge Local Examinations Syndicate- UCLES 2001. 


\section{Procedures}

Teacher Motivational Practice Index used to observe teacher motivational behaviour during class is, in fact, the sum of two different but complementary measures: (a) the observational data based on the minute-by-minute record of the teachers' behaviours during class time obtained through the application of MOLT (which was also used to record student motivational/demotivationalbehavior), and (b) the retrospective evaluation of the teachers' professional qualities, performed right after each observed session by means off utilizing the Post-Lesson Teacher Evaluation scale. The teachers were notified that the study aimed to investigate their students' behaviors during class activities regardless of what the activities were and how they were performed. It was emphasized that teachers' behavior was not the focus of the study and that the researcher was interested in the students' actions. They were assured that they did not need to worry about their teaching quality and main purpose was to observe what they normally do in their classes. The questionnaires were administered at the end of the classes after completing the observation sheets by the researcher. The completion of the questionnaires lasted about 10 minutes and the standard class time was 90 minutes. Finally, the observer completed the Post-Lesson Teacher Evaluation scale right after each teaching session. Concerning the differences between high-motivation and lowmotivation EFL learners in terms of their motivation/demotivation levels and their influence on Iranian EFL Learners production of request and refusal speech acts, the classes were ordered from the highest to the lowest motivation groups based on their level of motivated/demotivated behavior obtained through the Motivational Orientation of Language Teaching classroom observation scheme (MOLT). The top one third (4 classes), the middle one third (4 classes), and the bottom one third (4 classes) groups were distinguished and labeled the high-motivation, moderate-motivation, and lowmotivation groups, respectively. Regarding the measurement of request speech acts production the aforementioned discourse completion task was used. In this process the DCT data was typed up, processed and classified into files based on the DCT combinations. Blum-Kulka, House, and Kasper (1989b) cited in Jalilifar (2009) classify requests into three major levels of directness: direct (Mood derivable, Performative, Hedged performative, Obligation statement, Want statements), conventionally indirect (Suggestory formula, Query preparatories) and non-conventionally indirect (Strong hint, and Mild hint).

Beebe et al. (1990) cited in Phuong (2006) classified refusal strategies as: direct (Performative, Non-performative statement (NO), Non-performative Negative willingness ability), indirect (Statement of regret, Statement of wish, Excuse/reason/explanation, Statement of alternative, Set condition for future or past acceptance, Promise of future acceptance, Statement of principle, Rhetorical question, Threat/statement of negative consequences, Restatement, Unwillingness/insistence, Postponement), and Adjuncts to Refusals (Statement of positive opinion/feeling or agreement, Statement of empathy, Addressing terms). In order to see if the classification was reliable and the specified groups represented truly different motivation groups, an independent samples t-test was run. Then they were non-randomly assigned to three groups of high-motivation, moderate-motivation, and low-motivation groups and after 
running a pre-test speech acts (DCT) questionnaire, during a 10 session teaching period request and refusal speech acts were taught to them. Finally, the same questionnaire was run as the posttest. Pearson correlation was then employed to find the relationship between the (subscales of the) students' demotivation and their production of request and refusal speech acts. The process of data analysis was performed based on framework developed by Blum-Kulka et al. (1989) and Beebe et al. (1990), and Phuong's (2006) particular coding schemes. Finally the same questionnaire was run as the post-test. The results of post - tests are presented in the next section. All the statistical procedures were conducted using the SPSS software version 22.

\section{FINDINGS}

\section{Findings for Research Question One}

The first research question of the study was: Does teacher motivational practice influence Iranian EFL Learners' production of request speech acts? To answer this research question, the request speech act posttest scores of the students in the high motivation index teachers' (HMIT) classes were compared with those of the students in the low motivation teachers' (LMIT) classes through a one-way ANCOVA, which could control for any possible differences in the pretest scores of the two groups of students and compare their posttest scores. The results of the ANCOVA analysis are presented below:

Table 1

Descriptive Statistics for Comparing the Request Speech Act Posttest Scores of the HMITs and LMIT's Students

\begin{tabular}{llll}
\hline Groups & Mean & Std. Deviation & $N$ \\
\hline HMITs' Students & 7.13 & 1.22 & 146 \\
\hline LMITs' Students & 5.24 & .91 & 154 \\
\hline Total & 6.16 & 1.43 & 300
\end{tabular}

Such descriptive statistics as mean and standard deviation are shown for both HMITs and LMITs' students in Table 1 . The request speech act posttest mean score of the students in HMITs' classes $(M=7.13)$ was found to be greater than those of students in LMITs' classes $(M=5.24)$. To determine whether this difference was a statistically significant one or not, the researcher had to look down the Sig (2-tailed) column in the ANCOVA table below:

Table 2

Results of one-way ANCOVA for comparing the request speech act post-test scores of the HMITs and LMIT's students

\begin{tabular}{lllllll}
\hline Source & $\begin{array}{l}\text { Type III Sum of } \\
\text { Squares }\end{array}$ & $d f$ & $\begin{array}{l}\text { Mean } \\
\text { Square }\end{array}$ & $F$ & Sig. & $\begin{array}{l}\text { Partial Eta } \\
\text { Squared }\end{array}$ \\
\hline Corrected Model & 270.47 & 2 & 135.23 & 116.35 & .00 & .43 \\
\hline Intercept & 1854.44 & 1 & 1854.44 & 1595.53 & .00 & .84 \\
\hline Pretest & 2.68 & 1 & 2.68 & 2.31 & .12 & .008 \\
\hline Groups & 264.93 & 1 & 264.93 & 227.94 & .00 & .43 \\
\hline Error & 345.19 & 297 & 1.16 & & & \\
\hline Total & 12024.00 & 300 & & & & \\
\hline Corrected Total & 615.66 & 299 & & & & \\
\hline
\end{tabular}


In Table 2, if you find Groups in the leftmost column and read across this row, under the Sig. column, you can find the $p$ value, which should be compared with the pre-set significance level (which is .05). The $p$-value here was smaller than the specified level of significance $(.00<.05)$, indicating that there was a statistically significant difference between the students in HMITs and LMITs' classes with respect to their request speech act posttest scores. Under Partial Eta Squared, the relevant value across the Groups row was .43, which shows that being in either HMITs or LMITs' classes accounted for $43 \%$ of the variance in the request speech act posttest scores of the students. Another noteworthy piece of information in Table 4.2 concerns the influence of the covariate (i.e. the pretest scores). If you find the line in the table that corresponds to the covariate (i.e. the Pretest), and read across to the Sig. level, you can see that the $p$-value here was .12 , which was greater than the significance level, meaning that the covariate was not significant. In fact, it could barely explain around $1 \%$ of the variance in the request speech act post-test scores of the participants.

\section{Findings for Research Question Two}

The penultimate research question of the study asked: Does teacher motivational practice influence Iranian EFL Learners' production of refusal speech acts? To answer this research question, the procedure adopted for the preceding research question was adopted again. That is, the refusal speech act posttest scores of the students in the HMITs' classes were compared with those of the students in the LMITs' classes using one-way ANCOVA:

Table 3

Descriptive statistics for comparing the refusal speech act posttest scores of the HMITs and LMIT's students

\begin{tabular}{llll}
\hline Groups & Mean & Std. Deviation & $N$ \\
\hline HMITs' Students & 7.31 & 1.12 & 146 \\
\hline LMITs' Students & 5.28 & .98 & 154 \\
\hline Total & 6.27 & 1.43 & 300 \\
\hline
\end{tabular}

Table 3 shows that the refusal speech act posttest mean score of the students in HMITs' classes $(M=7.31)$ was found to be greater than those of students in LMITs' classes $(M$ $=5.28$ ). To find out whether this difference was a statistically significant one or not, the researcher had to take a glance down the Sig (2-tailed) column in the ANCOVA table below (Table 4):

Table 4

Results of one-way ANCOVA for comparing the refusal speech act posttest scores of the HMITs and LMIT's students

\begin{tabular}{lllllll}
\hline Source & Type III Sum of Squares & $d f$ & Mean Square & $F$ & Sig. & Partial Eta Squared \\
\hline Corrected Model & 309.28 & 2 & 154.64 & 149.94 & .00 & .50 \\
\hline Intercept & 1815.96 & 1 & 1815.96 & 1760.79 & .00 & .85 \\
\hline Pretest & .62 & 1 & .62 & .61 & .43 & .002 \\
\hline Groups & 306.98 & 1 & 306.98 & 297.65 & .00 & .50 \\
\hline Error & 306.30 & 297 & 1.03 & & & \\
\hline Total & 12422.00 & 300 & & & & \\
\hline Corrected Total & 615.58 & 299 & & & & \\
\hline
\end{tabular}


The $p$ value in front of Groups in Table 4.4 was smaller than the specified level of significance $(.00<.05)$, which means that there was a statistically significant difference between the students in HMITs and LMITs' classes concerning their refusal speech act post-test scores. Under Partial Eta Squared, the value across the Groups row was .50, which indicates that being in either HMITs or LMITs' classes accounted for $50 \%$ of the variance in the refusal speech act posttest scores of the students. Moreover, the influence of the covariate (i.e. the pre-test scores) was not significant since the $p$-value was found to be .43 , which was greater than the significance level.

\section{Findings Results for Research Question Three}

Finally, the third research question of the study was: What is the relationship between student demotivation and Iranian EFL learners' production of request and refusal speech acts? To provide an answer to this research question, Pearson correlation was employed to find the relationship between the (subscales of the) students' demotivation and their production of request and refusal speech acts:

Table 5

Results of pearson correlation for the relationship between the subscales of students' demotivation and their production of request and refusal speech acts

\begin{tabular}{|c|c|c|c|c|}
\hline \multirow{10}{*}{ 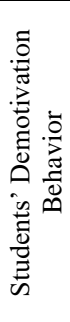 } & & & Request Speech Act & Refusal Speech Act \\
\hline & \multirow{3}{*}{ Alertness } & Pearson Correlation & -.36 & -.42 \\
\hline & & Sig. (2-tailed) & .00 & .00 \\
\hline & & $N$ & 300 & 300 \\
\hline & \multirow{3}{*}{ Volunteering } & Pearson Correlation & -.41 & -.38 \\
\hline & & Sig. (2-tailed) & .000 & .00 \\
\hline & & $N$ & 300 & 300 \\
\hline & \multirow{3}{*}{ Participation } & Pearson Correlation & -.59 & -.61 \\
\hline & & Sig. (2-tailed) & .00 & .00 \\
\hline & & $N$ & 300 & 300 \\
\hline
\end{tabular}

Table 5 shows that the relationships between all the subscales of the students' demotivation (i.e., lack of alertness, volunteering, and participation) and their production of request and refusal speech acts were negative relationships. In fact, the relationships between (lack of) alertness and request/refusal speech acts were weak, negative, and significant. In addition, the relationships between (lack of) participation and request/refusal speech acts were moderate, negative, and significant. Pearson correlation analysis was employed again to find the relationship between the composite variable of students' demotivation and their production of request and refusal speech acts, the results of which are presented in Table 6:

Table 6

Results of pearson correlation for the relationship between students' demotivation and their production of request and refusal speech acts

\begin{tabular}{llcc}
\hline & & Request Speech Act & Refusal Speech Act \\
\hline Students' & Pearson Correlation & -46 & -47 \\
\cline { 2 - 4 } $\begin{array}{l}\text { Demotivation } \\
\text { Behavior }\end{array}$ & Sig. (2-tailed) & .00 & .00 \\
\cline { 2 - 4 } & $N$ & 300 & 300 \\
\hline
\end{tabular}

Table 4.6 shows that the relationships between students' demotivation and their production of request and refusal speech acts were weak negative relationships (i.e., $r=$ 
-46 and $r=-47$ respectively). On the face of being weak correlations, both of these two negative relationships were statistically significant $(p=.00)$. The conclusion thus could be that lower levels of demotivation are associated with higher abilities in the production of the speech acts of request and refusal and vice versa.

\section{DISCUSSION}

This study was in fact an attempt to shed light on the point whether teacher motivational practice and student demotivation could bear any influence on the request and refusal speech acts production of Iranian EFL students or not. Rose (2000) held that studying pragmatic development requires cross-sectional studies with participants at various stages of development. Accordingly, the present study was designed as a cross-sectional research which involved language learners at upper intermediate level. The results of data analysis for the first research and second questions showed that that the students who were in high-motivation-index teachers' classes had developed a sharper sense of recognizing the speech act of requests and refusals which means teacher motivational practice does influence Iranian EFL Learners' production of request and refusal speech acts. This conclusion is in line with Teven and McCroskey, (1997) and Frymier and Houser, (2000) which believe that a good interpersonal relationship between the teacher and the learners poses direct and indirect influences on learning processes on the bases that affective learning is shaped by learners' behavior toward the teachers' impact on learners' cognitive orientations (Ellis, 2000). In the same direction of belief, MacIntyre, (1999) and Young, (1999) believe that a supportive classroom climate also helps to encourage students to learn a language when they feel they are protected. In the same vein,OKO (2014) also examined the impact of teacher motivation on academic performance of students. It proceeded by defining teacher motivation as a general term applying to the entire class of drives, desires, needs, wishes and similar forces initiated for teachers, in order to induce students to act in desirable academically productive manner. And finally,it could be claimed that lower levels of demotivation are associated with higher abilities in the production of the speech acts of request and refusal and vice versa which is in line with $\mathrm{Hu}$ (2011) who aimed at investigating the relationship between technological institute EFL students' past demotivating factors and their English language proficiency.

\section{CONCLUSION}

As it was illuminated, the findings of the study revealed that, there is statistically significant difference between the students in HMITs and LMITs' classes with respect to their request speech act posttest scores. Based on the results obtained through the statistical analysis on the collected data for the second research question, it can be safely claimed that there is a statistically significant difference between the students in HMITs and LMITs' classes concerning their refusal speech act posttest scores. Finally it was seen that student demotivation is a detrimental factor in the abilities of the production of the speech acts of request and refusal. So it seems a must for the EFL curriculum developers at ministry of education and training, Isfahan, Iran to think about remedies for improving motivation among their EFL teachers for persuading their students to: realize the importance of English, recognize English as an international language , 
recognize English as a fundamental skill of educated people, find English as an easy language, make EFL them more interested and excited, and they themselves focus on communicative activities, provide more practical and real opportunities to use English in a class and so on. For further research, it is recommended to find the the relationship between teacher motivational practice and EFL learners' motivation/demotivation in other language learning areas. Other researchers also can observe EFL learners' speech acts production in relation to variables such as aptitudes, and learning strategies. Finally, the researchers hope this study can contribute to the other similar studies which deal with second language acquisition and learning. Furthermore Iranian educational system may use the results of this study to improve the language proficiency and speech acts production ability of Iranian high school students which in turn results in foreign language learning improvement.

\section{REFERENCES}

Alemi, M. \& Khanlarzadeh, N. (2017). Native and Non-Native Teachers Pragmatic Criteria for Rating Request Speech Acts: The Case of American and Iranian EFL Teachers. Applied Research on English Language V. 6 N. 12017 pp: 67-84 http://uijs.ui.ac.ir/are

Austin, J. (1975). How to Do Things with Words.2nd edn. Oxford: Oxford University Press. 1st edn. 1962.

Beebe, L. M.; Takahashi, T.\&Uliss-Weltz, R. (1990).Pragmatic transfer in ESL refusals. In R. Scarcella, E. S.Andersen, \& S. D.Krashen (Eds.),Developing communicative competence in second language (pp. 55-73). New York: NewburyHouse.

Blum-Kulka, S.; House, J. \& Kasper, G. (1989).Investigating cross-cultural pragmatics: An introductory overview. In S. Blum-Kulka, J. House, \& G. Kasper (Eds.), Cross-cultural pragmatics: Requests and apologies. (pp. 1-34). Norwood, NJ: Ablex.

Bronfenbrenner, U. (1993). The ecology of cognitive development: Research models and fugitive findings. In R. H. Wozniak \& K. W. Fisher (Eds.), Development in context: Acting and thinking in specific environments (pp. 3-44.). Hillsdale, NJ: Lawrence Erlbaum

Brown, D. H. (2000). Teaching by Principles: An Interactive Approach to Language Pedagogy (4th Ed.). USA: Longman.

Deveci, T. \&Hmida, I. (2017).The request speech act in emails by Arab university students in the UAE.Journal of Language and Linguistic Studies, 13(1), 194-214; 2017

Dörnyei, Z. \& Scott, M.L. (1997). Review Article Communication Strategies in a Second Language: Definitions and Taxonomies. Language Learning. 47(1), 173-210.

ElahiShirvan, M. \&Taherian, T. (2016) Dynamic emergent patterns of L2 willingness to communicate within the ecology of the classroom.Konin Language Studies.Faculty of Philology, State University of Applied Sciences in Konin, Poland KSJ 4 (4). 2016. 415-438 http://ksj.pwsz.konin.edu.pl

Ellis, K. (2000). Perceived teacher confirmation.Human Communication Research, 26, 264- 292.

Eslami-Rasekh, Z. (2005). Raising the pragmatic awareness of language learners.ELT Journal, 59, 199-208.

Frymier, A. \& Houser, M. (2000).The teacher-student relationship as an interpersonal relationship.Communication Education, 49(3), 207-219. doi:10.1080/03634520009379209 
Guilloteaux, M. J. \&Dörnyei, Z. (2008). Motivating Language Learners: A Classroom Oriented Investigation of the Effects of Motivational Strategies on Student Motivation, TESOL Quarterly, 42(1), 55-77.

Hassani, R.; Mardani, M., \& Hossein, H. (2011). A Comparative Study of Refusals: Gender Distinction and Social Status in Focus. The International Journal - Language Society and Culture (32), 37-46.

Hein, V. (2012). The Effect of Teacher Behavior on Students Motivation and Learning Outcomes: A Review.ActaKinsiologiaeUniversitatis, 2012, Vol. 18, pp.9-19

Hu, R. J. S. (2011). The Relationship between Demotivation and EFL Learners' English Language Proficiency.English Language Teaching, 4(4): 88-96.

Jalilifar, A. R. (2009). Thematic development in English and translated academic texts. Journal of Language and Translation, 10(1), 81-111.

Kakar, S. \& Pathan,Z. (2017) . Exploring the Motivational Strategies Practiced by Pakistani EFL Teachers to Motivate Students in Learning English Language. International Journal of English Linguistics; Vol. 7, No. 2; 2017 ISSN 1923-869X E-ISSN 1923-8703 Published by Canadian Center of Science and Education

Koike, D. A. (1989). Pragmatic competence and adult L2 acquisition: Speech acts in interlanguage. The Modern Language Journal, 73(3), 279-289.

Kuhi, D. \& Jadidi, M. (2012). A study of Iranian EFL learners' understanding and production of politeness in three speech acts Request, refusal, and apology. Theory and Practice in Language Studies, 2(12), 2624-2633.

Leech, G. (1983). Principles of Pragmatics [M]. London: Longman.

Li, C. \& Zhou, T. (2017).An Exploratory Study on the Relationship between Demotivation and Academic Fields among Chinese EFL Learners.Arab World English Journal (AWEJ) Volume.8 Number.1 March 2017. DOI: https://dx.doi.org/10.24093/awej/vol8no1.4

Likert, R. (1932). A Technique for the Measurement of Attitudes.Archives of psychology, 22(140), 1-55.Lipsky, G. A. (1959). Saudi Arabia: Its People, Its Society, Its Culture. New Haven. Conn.: HRAF Press.

MacIntyre, P. D. (1999). Language anxiety: A review of the research for language teachers. In G. J. Young (Ed.), Affect in Foreign language and second language learning. Boston: McGraw-Hill. 24-45.

Mahmud, M. (2017).Communicative Styles of English Students at the State University of Makassar. Journal of Language Studies Volume 17(1), February 2017 http://doi.org/10.17576/gema-2017-1701-13

MashhadiHeidar, D.; Pahlavan , M. \&Kavian, M. (2017)Sociological Study of Motivation and its Effect on Iranian Teachers' Learning English. Journal of Social Studies of Youth. ISSN: 2476-5198, SSYJ 2017, 7 (24), 49-60

Mehrpour, S.; Ahmadi, M. \&SabourianZadeh, N. (2016).Cross-linguistic Comparison of Refusal Speech Act: Evidence from Trilingual EFL Learners in English, Farsi, and Kurdish. Iranian Journal of Applied Language Studies, Vol 8, No 2, 2016

Melekoglu, M. A., \& Wilkerson, K.L. (2013). Motivation to read: How does it change for struggling readers with and without disabilities?.International Journal of Instruction, 6(1), 77-88 
Memarian, P. (2012). The use of request strategies in English by Iranian graduate students: A case study (Unpublished master's thesis). Eastern Mediterranean University, Gazimağusa, North Cyprus.

OKO, O. (2014). Impact of Teacher Motivation on Academic Performance of Students.

National Association of Mathematics Students' Conference/Seminar held at the College Auditorium, NwaforOrizu College of Education, Nsugbe, Anambra State, Nigeria Date: 19th - 23rd November 2014

Papi, M. \&Abdollahzadeh, E. (2012). Teacher motivational practice, student motivation, and possible L2 selves: An examination in the Iranian EFL context. Language Learning, 62(2), 571-594.

Phuong, N.T.M.(2006). Cross-cultural pragmatics: refusals of requests by Australian native speakers of English and Vietnamese learners of English. Unpublished master's thesis University Of Queens, New York City, USA.

Qadoury, A. A. (2011). Pragmatic Transfer in Iraqi EFL Learners' Refusals.International Journal of English Linguistics, 1 (2), 66.

Rastegari, S. \&Narafshan, M. (2017). Fostering EFL Learners' Motivation: Quick and Narrow Listening Strategies. Journal of Advances in English Language Teaching 2017; Vol.5 No.2 pp. 13-24 ISSN 1805-8957

Rose, K. R. (2000). An exploratory cross-sectional study of interlanguage pragmatic development.Studies in Second Language Acquisition, 22, 27-67.

Salikin, H.; Bin-Tahir, S., Kusumaningputri, R. \& Yuliandari, D. (2017). The Indonesian EFL Learners' Motivation in Reading.English Language Teaching; Vol. 10, No. 5; 2017 ISSN 1916-4742 E-ISSN 1916-4750 Published by Canadian Center of Science and Education

Searl, J. R. (1969). Speech acts: an essay in the philosophy of language . Cambridge: Cambridge University Press.

TamimiSa'd, H. \&Gholami, G. (2017). Teaching Iranian Elementary EFL Learners to Say 'No' Politely: An Interlanguage Pragmatic Study. The Electronic Journal for English as a Second Language May 2017 - Volume 21, Number 1

Teven, J. J. \& McCroskey, J. C. (1997).The relationship of perceivedteacher caring with student learning and teacher evaluation.Communication Education, 46, 1-9.

Veysel, A. (2018). Teaching Mathematical Functions Using Geometric Functions Approach and Its Effect on Ninth Grade Students' Motivation.International Journal of Instruction, v.11 n1 p17-32 Jan 2018

White, R. (1993). Saying please: pragmalinguistic failure in English interaction.ELT Journal, 193-202

Wolfson, N. (1981). Compliments in cross-cultural perspective [J].In TESOL Quarterly 15,117-24.

Wu, J. \& Lee, M. (2017). The relationships between test performance and students' perceptions of learning motivation, test value, and test anxiety in the context of the English benchmark requirement for graduation in Taiwan's universities. Language Testing in Asia (2017) 7:9 DOI 10.1186/s40468-017-0041-4 